2. It is widely applicable, as its toxicity is small. Oardiac disease, syphilis of the nervous system, and concomitant grave maladies are its chief contra-indications. 3. The intravenous method is the only recommendable one. 4. Repeated medium doses are preferable to a few large ones. 5. Its use is indicated where mercury has failed.

6. In very early cases an attempt at aborting the disease by excising the chancre and administering salvarsan is advisable. 7. In florid secondary syphilis combined salvarsan and mercury treatment should be instituted and persevered with. 8. The severe tertiary cases should also be submitted to this combined treatment. 9. In mild tertiary cases salvarsan recommends itself by the rapidity of the removal of the lesions, and by the long duration of the subsequent latency. 10. Truly malignant cases are as hopeless under salvarsan treatment as otherwise. 11. In late latent cases and in parasyphilis the administration of salvarsan presents no utility.

My sincere thanks are due to Mr. Ernest Lane for the liberal way in which he allowed me to make use of his large clinical material.

\section{SYPHILITIC AORTITIS WITH VALVULAR INCOMPETENCY.}

By AIEXANDER MORISON, M.D. EDIN., F.R.C.P. EDIN. \& LOND.,

SENIOR PHYSICIAN TO THE GREAT NORTHERN CENTRAL HOSPITAI,

THE object with which the living patient (if one may for convenience use that unnecessary qualification) is presented, is, to illustrate some points which serve to distinguish the type of aortic valvular disease he represents from that of which the deceased patient was a pronounced example.

CASE 1. Aortio valvular disease from rherimatic endocarditis. -The patient is a man, 22 years of age, who has been under my observation at the Great Northern Central Hospital since he was a boy of 13. At a still earlier age he had suffered from rheumatic fever, and when he first came to hospital he had the usual clinical signs of aortic regurgitant disease with consecutive hypertrophy. When 19 , incapacitated for all work and suffering much from anginoid pain, a præcordial thoracostomy was performed upon him for me by $\mathrm{Mr}$. Ewen C. Stabb, with great relief to his symptoms. An account of the case was published in THE LANCET of July 4th, 1908. He was also shown at the Polyclinic among other patients about two years ago, and it may interest you to examine him again, being as he is in comparative comfort and earning his livelihood by a light occupation.

My chief reason, however, for showing him now is that he was the most typical case of aortic valvular disease from rheumatic endocarditis which $I$ could at the moment produce in order to indicate the differences between cases of this kind and those of specific aortitis with aortic valvular incompetency, of which I purpose speaking presently. He also illustrates instructively the importance of the purely mechanical factor in heart disease.

We have here the case of a young man giving an early history of rheumatic fever, followed by aortic valvular disease, and the gradual increase of the heart in ventricular bulk and power, to conduct the blood-How, rendered more difficult by the mechanical valvular lesion. This stage is followed by one in which a powerful ventricle is caged and limited in its effective output of energy by skeletal embarrassment, and exhausted by the effort of raising the resistant chest wall, in addition to driving the blood. Relieved by operation from this additional work, and having now to deal chiefly with the difficulty due to valvular defect, the hypertrophied organ accomplishes its task with comparative ease and with greatly lessened discomfort to the patient.

OASE 2. Syphilitio antitis nith valvular incompetenoy.The other case, represented here only by his heart, was that of a man, 37 years of age, who was admitted under my care at the Great Northern Central Hospital on May 6th, 1911. More recently he had been man-servant to a gentleman, by

1 Being, based on a clinical demonstration given at the Medical Graduates' College and Polyclinic. The demonstration consisted in the exhibition of one patient and the consideration of the case of another, prepared from it. whom in illness he had been treated with much consideration. He had formerly been a soldier and served in the Boer War. After his return from that campaign he stated that he had suffered from rheumatism, but had never had rheumatic fever. His general health, he maintained, had always been excellent, and he denied having ever had syphilis. This history, as I shall show, was incorrect on a material point.

In November, 1910, he began to suffer from shortness of breath and was placed in a nursing home in December and the following January. Since that time, and until his admission to the Great Northern Central Hospital, he had done little work. Exertion was stated to induce epigastric pain.

When admitted he was seen to be a well-developed man suffering little when at rest. There was no cedema, dyspncea, or pain. The organs generally were sound except the heart; with this, the apex beat was visible in the sixth intercostal space, 2 inches to the left of the nipple line. ${ }^{*}$, The right limit of cardiac dulness was half an inch to the right of the sternum and the upper limit in the second intercostal space. There was a disastolic bruit andible in a curved line, with the convexity to the left, from the right cardiac base to the apex, and a systolic bruit is noted in the record as audible at the apex itself. The aortic diastolic bruit was, however, the chief sign of valvular defect. The pulse-rate was 90 and the rhythm regular. The temperature was normal.

Until the beginning of June he was apparently benefited by rest and general treatment. The note on June 1st is that the heart's apex beat was an inch and a half to the left of the nipple line, its action quite regular, the pulse-rate 88 , and the diastolic bruit rather less distinct, but still loud. The patient expressed himself as feeling much better.

After this, however, his condition became less satisfactory. He lost strength, and anasarca showed itself and steadily increased. From June 15th to July $7 \mathrm{th}$, as cardiac failure was progressive, digitalis in considerable doses was administered. The patient took from 15 to 20 minims of the tincture every four to six hours, but without effect upon the rate or rhythm of the pulse. It was now thought desirable, although syphilitic infection was positively denied, to determine the point by Wassermann's test, which was first employed by the pathologist to the hospital (Mr. Ernest Shaw) on July 6th, when it was found to be positive on this and six subsequent occasions. The result was so typical that the patient's blood was used as a standard in examining. other cases of suspected syphilis in the hospital. Specific treatment was used, but with negative result, which was to be anticipated under the circumstances.

On July 26th the patient suddenly became a good deal worse. He had a sudden attack of pain in the præcordia with dyspncea and extreme pallor. He had, in short, an attack of angina pectoris-the only attack while in hospital -and required vigorous stimulation to recover. Next day he was somewhat better. On July 28th cardiac arrhythmia was observed for the first time. It was of a regular type, although the ventricular panse occurred at the end of series of seren and ten pulsations. The heart-rate was 114 to 120 . The arrhythmia did not persist, and at no time was there any ventricular retardation. He gradually sank, showing progressive enfeeblement of pulse, and died on August 2nd.

In view of the anatomical changes found post mortem the following further particulars of the temperature and heart's action may be given. The temperature was normal or slightly subnormal during the first five weeks after admission, with the exception of one day, when it only reached $99.6^{\circ} \mathrm{F}$ During this period the pulse-rate ranged from 82 to 100 , and only on one occasion reached the latter figure. In the sixth week the temperature reached $100^{\circ}$, when the pulse also on one occasion was 100 . The seventh and eighth weeks were uneventful in this respect, the temperature and pulse-rate being as before. In the ninth week the evening temperature was slightly raised, but the bighest recorded was $99.6^{\circ}$, and the pulse ranged from 90 to 104 . The tenth week began with a subnormal temperature and ended with a slight rise above normal, which then fell for three days to subnormal, but rose on July 25 th to $100 \%$, the pulse becoming quicker and feebler and the respiration accelerated. In the lethal exitus, which lasted from July 27th to August 2nd, the temperature reached its highest point (from $100^{\circ}$ to $100 \cdot 8^{\circ}$ ), the pulse-rate rising from 114 to 132 and the respiration from 30 to 40 . On two 
FIG. 1.

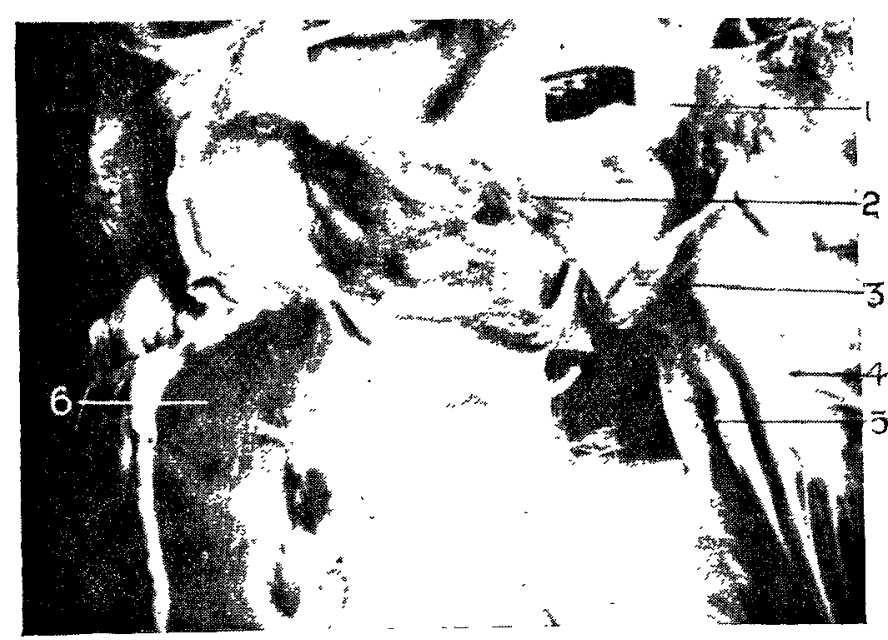

FIG. 3.

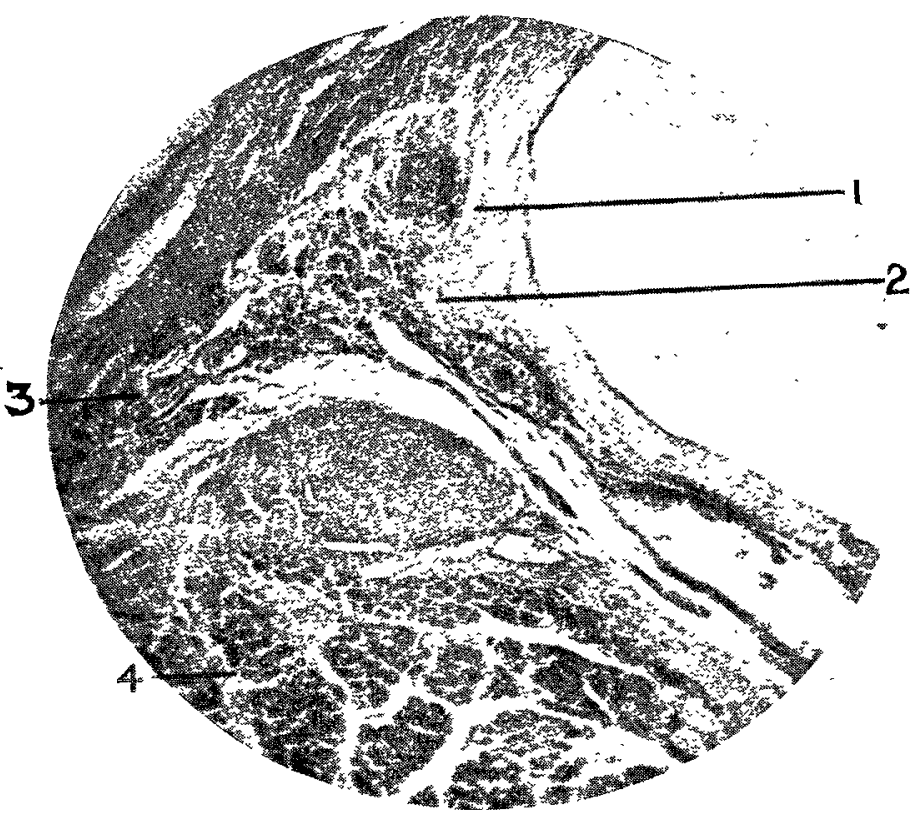

FIG. 5.

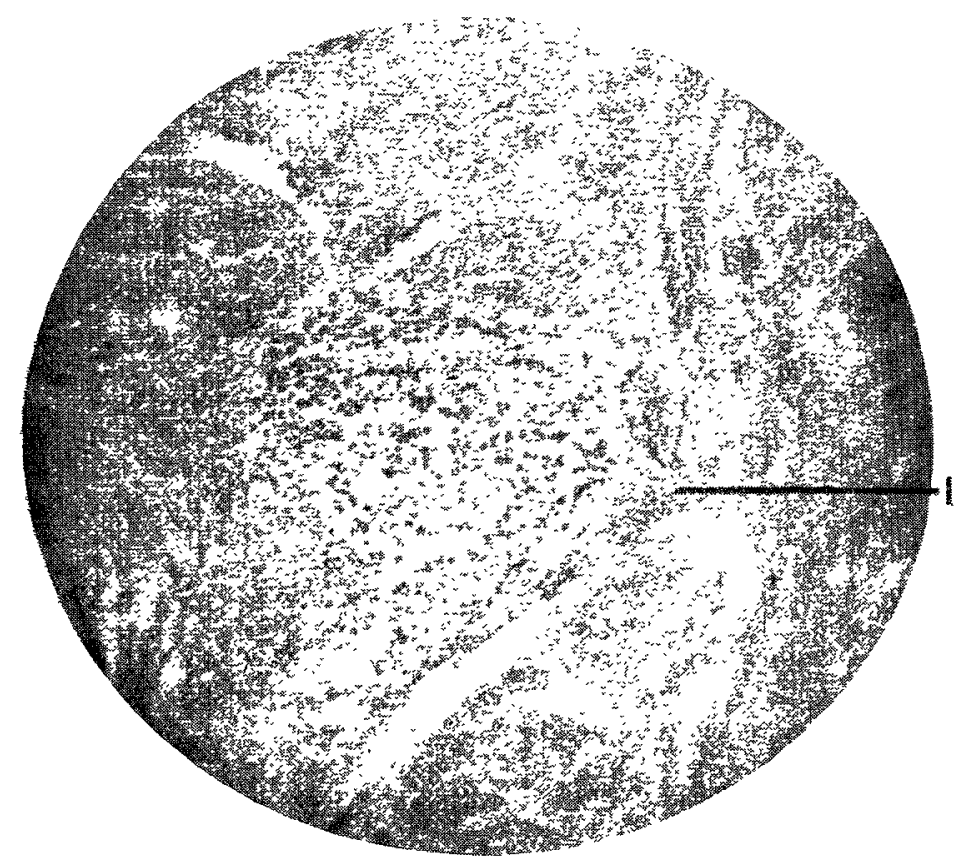

FIG. 2.

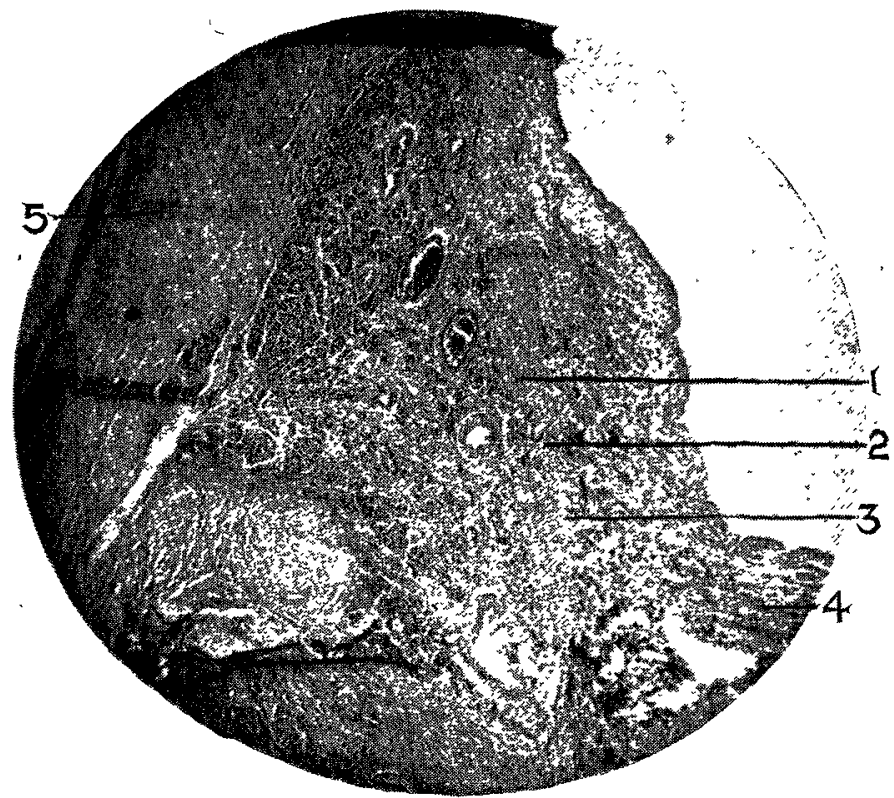

FrG. 4.

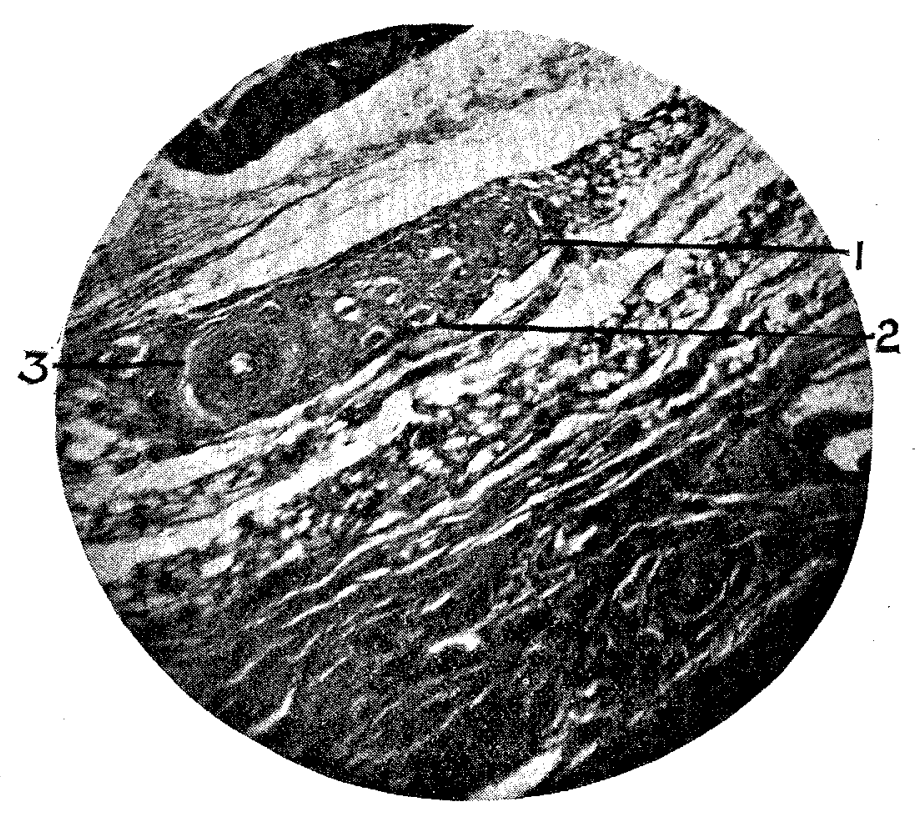

DESGRIPTION OF ILLU'STRATIONS.

FIG. 1.-Syphilitic aortitis. 1. Portion removed for examination 2. Right coronary artery with surrounding puckering. 3. Noncoronary aortic cusp. 4. Mitral valve. 5. Portion removed for examination of the bundle. 6. Left ventricular wall.

FIG. 2.-First portion of the auriculo-ventricular bundle. 1. Fibrosis of the bundle. 2. Endarteritic thickening of bloodvessel. 3. Right limb of the bundle. 4. Portion of the septal cusp of the tricuspid valve. 5. Pars membranacea septi. Swift's objective 1 in.

FIG. 3.-Later portion of the bundle. 1. The large obliterated artery with obliterated branch. 2. The right limb of the bundie. 3. The left ventricular limb of the bundle, showing considerable inuscular atrophy. 4. Left rentricle. Swift objective $\frac{1}{3}$ in.

FIG. 4.-Atrophied nerve cells in selerosed ganglion. 1. Almost obliterated artery. 2. Atrophic cells. 3. Larger artery almost obliterated. Swift objective! in.

FIG. 5.-Gumma in aortic wall. 1. Gumma. Swift objective $\frac{1}{6}$ in. 
days between these dates the temperature fell to subnormal and the pulse-rate and respiration fell with it.

Necropsy.-At the post-mortem examination-which was made by the pathologist to the hospital-a little fluid was found in both pleuræ. The lungs were congested, dry, and tough. There were several hæemorrhagic infarcts visible under the pleuræ, and one of them was decolourised and softened and had evidently existed for some days. The pericardium contained a little clear fluid; there was a large milk spot on the anterior surface of the heart and $a$ few petechix behind. From the right auricular blood the bacillus coli communis was grown.

The heart itself weighed, with contained blood, $38 \mathrm{oz}$, and without it $25 \mathrm{oz}$. The organ was firm and heavy, and the muscle rather paler than normal. The dextral valves were normal. The left ventricle was much dilated, and the mitral orifice admitted three fingers and was six inches in circumference. The cusps were rather thickenerl and narrow The left auricle was large. The coronary arteries opened higher up in The loft an the aorta

The aorta was extremely, atheromatous aud rather dilated, and showed two small bulgings just above the valves. The surface of the vessel was much puckered, as the photograph (Fig. 1) shows, and there were no calcareous patches. The valves were distorted and in was markedly thickened. The abdominal organs showed no other was markedly thickened. The abdominal

change than resulted from a passive congestion.

Microscopical examination.-I later examined portions of the heart and aorta microscopically, with the following results :-

The arteries, chiefly in the auricles and interauriclar septum, in the pars membranacea septi, and in the peri-aortic cellular tissue, showed advanced obliterative endarteritis. In one section a large artery and its branches, immeriately above the auriculo-ventricular bundle, were completely obliterated and showed advanced connective tissue production and total disappearance of all muscular elements. The auriculo-

ventricular bundle was likewise shot with an excess of veins.

While the ventricular muscle showed here and there marked fibrosis the auricular muscle and interauricular septum 'were most affected by fibrotic changes with interstitial nucleolysis. The first portion of the auriculo-ventricular bundle, before definite bifurcation (Fig. 2), shows advanced sclerosis with nucleolysis, and especially in its right half. The muscular element itself is exsanguinated and atrophied in parts After the bundle has definitely bifureated, in the neighbuirh parts completely obliterated large artery above completely obliterated large artery above referred to (Fig. 3), the sam atrophic condition of muscle is observable, but most so in the left ventricular limb of the bundle. Ganglionic nerve cells, lying betwee vessels largely obliterated, show atrophy of the cell elements (Fig. 4) and in other parts nerve bundles exhibit a hyper-nucleolysis. The well-marked gummatous nucleolytic deposits in its fibrous sheath.

Gumma may, of course, also occur in the musculo-fibrous coat of the aorta, as is shown in Fig. 5, taken from another case of syphilitic aortitis, which died from rupture of an abdominal aneurysm. The sino-auricular ganglia were missed in the case $I$ have related at length, in an endeavour to procure a horizontal section, but I have found some cells of the ganglia to be atrophic in another case of cardiac syphilis, without any disorder of cardiac rhythm resulting.

Remarks.-Syphilitic disease of the heart and aorta, apart from aneurysm, has, since Ricord's day, been studied by many authors. In THE LANCET in $1897^{2}$ there is an excellent article on syphilis of the myocardium by Dr. Sidney Phillips, who refers to previous work on the subject. Sir William Osler and Dr. Mitchell Bruce dealt with the matter in their Lumleian lectures, ${ }^{3}$ and Sir Olifford Allbutt has, by publications extending over a lengthened period, made the "suprasigmoid portion" of the aorta his own." Foreign medical literature also deals with the condition fully.

These facts notwithstanding, syphilitic aortitis with valvular incompetency, though a distinct clinical entity, is a type of valvular disease which is not always recognised as such, although, with reasonably careful investigation and reflection, it should not fail to be detected. A comparison of the two cases to which $I$ have referred above serves to indicate the chief elements in clinical diagnosis. Of the rheumatic type I have already spoken.

The patient affected with specific aortic valvular disease is usually a man, and generally comparatively young, but not a youth. His age varies from 30 or 35 to about 50 . Even on careful investigation, and as a rule, no history of rheumatic or scarlet fever is to be elicited. Nor is there a history of physical disability in earlier life. The patient has usually followed some active calling, and often that of a soldier or sailor. Ultimately he becomes dyspnoeic on exertion, frequently complains of attacks of pain in his chest or epigastrium, and on examination reveals aortic valvular disease with consecutive enlargement of the organ.

If he fail to respond to treatment (as he frequently does at the stage at which he presents himself) and die, the necropsy reveals an atheromatous aorta and puckering of the valves,

2 The Lancer, Jan. 23 rd, 1897, p. 223

3 The LANCET, March 26th, 1910, p. 839 ; and THE LANCET, July 8th, 1911, p. 69.

4 System of Medicine, vol. vi. which, considering the comparative youth of 'thelpatient in most cases, and an absence of the history of the usual acute infections which induce heart disease, leads, even when syphilitic infection is denied, to a diagnosis of the consequences of that condition. More minute investigation of the textures confirms the correctness of this view.

The clinical history and anatomical examination of the case I have related exemplify these facts in a typical manner. The case is also interesting because, although there were well-marked changes in the auriculo-ventricular bundle, such as have been described as occurring in cases exhibiting "heart-block" or the dissociated action of the auricles and ventricles, that condition was not present in this instance. Had it occurred partially or completely, the anatomical conditions found would have been considered by some quite sufficient to account for that state.

Dr. Thomas Lewis has collected and carefully analysed 50 cases of complete or partial heart-block, in 11 of which syphilitic invasion or affection of the auriculo-ventricular bundle was regarded as causal of that condition.

The anatomical changes, whether in nerve, muscle, or interstitial tissue, appear to be largely due in cardiac syphilis to that condition of the blood-vessels so characteristic of this state, which interferes with the due nutrition of the structures affected. The pulmonary infarction and bacillary heart blood of the case I have related was evidently a so-called terminal infection and had no bearing on the general clinical history:

Treatment. - As Sir William Osler has remarked with regard to the treatment of aortic anenrysm of specific origin, it is its prevention by suitable and sufficient treatment of the early infection which is most important. This doubtless holds good also for other ultimate manifestations of cardio-vascular syphilis. But to prevent is not to treat either aneurysm or aortitis. The frequently observed beneficial effects of the treatment of late manifestations of syphilis by mercury and the iodides justify, nevertheless, the expectation of benefit from this line of treatment in the type of case with which we have been dealing. But when cardiac failure has occurred in an advanced case such as I have related, little good can be expected to follow the use of any remedy, the anatomical changes described being permanent and important structures atrophied and impaired in function.

Although common experience teaches us that cardiac failure with a mitral lesion is more amenable to treatment by the digitalis group than a similar failure with aortic lesion, we know that digitalis has at times a well-marked effect in reducing the heart-rate in aortic valvular disease. The failure of these agents to do so in the case discussed has a certain interest, as it has been suggested that lesions of the bundle of His render the retardant action of the digitalis group on ventricular action more probable. Such a modus operandi of these agents is, however, at present, merely a supposition on the part of those who entertain it.

Upper Berkeley-street, $\mathbf{W}$.

\section{THE CLINICAL SIGNIFICANCE OF X RAY} AND RADIUM MEASUREMENTS. ${ }^{1}$

$$
\text { BY S. RUSS, D.Sc., }
$$

BEIT MEMORTAI RESEAROH FELLOW.

(From the Canoer Researoh Laboratories, Middlesen Hospital.)

IT is desirable for clinical and experimental biological purposes to have some comparative measurements between the intensity and character of the radiation from an $X$ ray bulb working under specified conditions and that from $a$ known quantity of radium. The character of the radiation from both is complex. Under whatever conditions an $\mathrm{X}$ ray bulb is working the radiation coming away from it is heterogeneous, consisting of rays varying in their penetrating power. The radiation from radium (and the short-lived products in equilibrium with it, Ra emanation $R a A, R a B$, and $\mathrm{RaC}$ ) consists of alpha, beta, and gamma rays, which are also heterogeneous in type.

Measurements have been made of the penetrability through

The Mechanism of the Heart Beat, 1911, pp. 102-105

1 A paper read before the Roentgen Society on Jan. 2nd, 1912 ? 